\title{
$R$
}

\section{Opportunities for the development of renewable energy in the EU}

\author{
by Juan Fraga, General Secretary EUFORES \\ European Forum for Renewable Energy Sources
}

The development that renewable energy sources (RES) are undergoing nowadays at all levels in the European Union (EU), was considered unbelievable just a few years ago. In 1994, when the $12 \%$ target for 2010 was first proposed (as 15\% equivalent substitution), present growth rates were simply disregarded as unrealistic. Today, however, renewables represent a key element of the present and future EU energy strategy, due to their important contribution to the reduction of greenhouse gas emissions and environmental protection, as well as their potential as a new high growth, labour-intensive sector, which is already so for many EU areas and for several technologies.

Not only are renewable energy sources, along with energy efficiency, crucial to the achievement of environmental targets such as the Kyoto commitments, but their indigenous and decentralised character can also contribute to increasing the security of supply in Europe, reducing dependency on fossil fuels imports and the risks associated to shortages or price instability, as rightly highlighted in the recently adopted Green Paper on Security of Supply.

Furthermore, the European renewable energy sector, which has experienced for some technologies double digit growth rates over the last few years, presents excellent results in employment creation and industrial development, and has still greater potential in this sense. A wide-ranging European study, which EUFORES initiated, has quantified "The Impact of Renewables on Employment and Economic Growth" using well well-established models. The study reveals a high labour intensity per energy unit produced, particularly in the field of biomass, and foresees a net employment creation of up to 900000 jobs by the year 2020, net meaning that no jobs would be created using conventional technologies. And, most significantly, an important part of this employment would be created in peripheral and rural areas, where it is most needed.

Substantial technological developments have brought the cost of RES technologies down, towards commercial maturity. Of course, there is still a lot to do in technological development of renewables, but technologies are mature enough to compete in the market, especially if the external costs of energy are taken into account, such as environmental damage, price volatility, security of supply, employment creation, etc., which will definitely make many renewable energy technologies more competitive than conventional technologies without any support.

Nonetheless, development has spread unevenly both between different renewable technologies and between different countries and regions throughout the EU. Despite the technological developments, the true potential of renewables is far from being tapped. For instance, in the United Kingdom, off-shore wind alone could generate more than four times the country's power requirement.

Unfortunately, there are still many barriers preventing market breakthrough of renewables. The process of liberalisation has changed market conditions, bringing in theory more 
competition, but yielding in practice less, as can be seen in the electricity market, which has undergone in most EU Member States through a concentration process. Furthermore, the energy market is still very distorted, and this situation will persist as long as external costs resulting from the whole energy cycle are not fully taken into consideration or, even worse, are passed on precisely just to those customers that choose energy sources that have minimal or none external costs.

Consequently, it is necessary to establish a level playing field if renewable energies are to be given a chance to compete in a fair market. A new emphasis should be put both on the supply side through compensation systems and on the demand side through adequate customer choice opportunities. And compensation is the key word: As long as external costs are not taken into account for energy prices, those energy sources that entail lesser costs or higher benefits should receive such compensation, wrongly considered subsidies by some.

\section{Moving towards a level playing field: Institutional activity}

Renewable energy sources are currently high on the EU political agenda. Several initiatives are being developed to achieve both a single market and a sustainable energy model. Although there is not a single, common energy policy (CEP) in the EU, the European Commission has launched several programmes and initiatives which affect energy and, more specifically, renewables. Indeed, a CEP and/or chapter on energy in the Treaties has been recently requested by the European Parliament.

The EU strategy for renewables, adopted on 1997 by the European Commission (EC) in a White Paper, sets common EU objectives for renewables, includes an Action Plan and a Campaign for Take-Off (CTO). The targets set, a $12 \%$ share in the total energy demand of the European Union by 2010, are considered by the European Commission as "ambitious but realistic".

The Directive 96/92/EC, on the liberalisation of the internal electricity market, adopted in December 1996, is also having an important impact on the development of renewables, with resultant deregulation and liberalisation processes in many Member States creating both new opportunities and threats. On the one hand a truly liberalised market could allow electricity consumers to choose their supplier and permit individual renewable energy producers to access the market. On the other hand, liberalisation also leads to mergers, job losses, and a market driven only by price. Furthermore, liberalisation increases the risk for investors, who then tend to focus on short term returns, preferring less capital intensive investment, which puts eco-efficient, but more capital-intensive technologies at a disadvantage.

Moreover, the current market liberalisation process is incomplete as conventional energies are still being subsidised, the market is not yet fully transparent (is it really?) and distortions are all over around. The liberalisation process is spreading slowly from large to smaller players, which leads to concentration in the absence of effective regulation. Indeed, market liberalisation must be accompanied by policy development to ensure fair market access for renewables. Deregulation should not lead to no regulation, but to reregulation, accordingly to the new market environment.

This concern and the need to harmonise access to the grid of electricity from renewable origin led to the Directive 2001/77/EC on electricity from Renewable Energy Sources (RES-E). The RES-E directive establishes a common target, $22 \%$ share of the electricity market, for the EU in 2010 and, for the first time, individual targets for electricity of renewable origin in each Member State, unfortunately indicative and not mandatory. 
Further political EU initiatives are nowadays in different discussion stages that could favour the take-off of sustainable energies, principally:

- the implementation mechanisms of the Kyoto Protocol, that will increasingly discourage greenhouse gas emissions, where renewables and efficiency are of the few really effective measures to achieve the commitments of the EU (estimated 20-30 $€$ per ton of $\mathrm{CO}_{2}$ );

- the proposals presently discussed for the harmonisation of energy taxation and on a EU-wide carbon levy, that aim at reducing taxes on labour and shifting these to exhausting resources, especially those that produce $\mathrm{CO}_{2}$;

- the recently adopted Directive on biofuels for transport;

- the ever-delayed proposal of a EU-wide discussion on the appropriate mechanisms to include external environmental, social and economic costs resulting from the whole energy cycle in the prices of conventional energies (the internalisation of externalities);

- the proposal of the European Parliament for a Common Energy Policy / Chapter and for a European Charter for Sustainable Energy, EURENEW, to set up a common, longterm framework for their development, plus much needed implementation and assessment tools;

- the horizontal integration of the priorities of the EU in its different activities, mainly in the fields of energy, environment, competition, agriculture and co-operation.

\section{Will renewables make it?}

The question is: Will the EU targets for renewables be met? And the answer to that, if current trends continue driving the energy market, is simply no. Renewables are presently growing at a faster rate than in the past times, that is true, but not enough to reach the ambitious goals recently set, and less so with an increase in consumption which is simply too high, due to the failure of energy conservation measures and to the failure in improving energy efficiency by reducing energy intensity.

Consequently, and as has been said, proactive policies are needed that foster an increased deployment and market penetration of renewables, as well as a market with fair competition rules, mainly by allowing transparency and true accounting of all the costs involved in the whole energy production, transportation and consumption process. Despite the discouraging news coming from the USA Administration (the origin of one fourth of all greenhouse gas emissions in the world), the urgency and seriousness of the problem remains.

It is, thus, more important than ever that the EU show strong political willingness to support renewables, and thus to increase significantly their market penetration. Renewable energy sources have a crucial role to play in achieving the reduction of greenhouse gas emissions and environmental protection, while ensuring the security of energy supply and contributing to economic development and employment creation. If the EU fails in this task, a great opportunity will be lost to switch to a truly sustainable energy model, both in environmental and economic terms.

For any further information, please, contact: eufores@eufores.org, www.eufores.org. 